\title{
REMAINS OF THE BEAUTY: A DEFINITION OF BEAUTY IN THE BUILT SPACE
}

\author{
SILVANA KÜHTZ \\ Department of European and Mediterranean Cultures: Architecture, Environment, Cultural Heritages (DiCEM), \\ University of Basilicata, Italy
}

\begin{abstract}
The study Cultural Heritage Counts for Europe (2015), demonstrated how cultural heritage is central to the processes of value production also in terms of its contribution to continuous social innovation. The focus is not only on the tangible and physical assets, but also on the intangible ones. Thoughts and beliefs stemming from very different historical and geographical contexts are confronting each other with increasing frequency. This research asks whether the cultural values and ideals we relied on in the last century are also somehow changing. In the light of modernity and of the present uncertainties (i.e. migrations, pandemic, etc.), we probably have to redefine and reaffirm what we took for granted during the second half of the 20th century, i.e. the idea of beauty. A series of interviews with experts to deepen the perception and definition of the concept of beauty are at the core of this paper.
\end{abstract}

Keywords: beauty and heritage, interviews, definition of beauty.

\section{INTRODUCTION}

The 2005 Faro Convention asserted that cultural heritage lies at the centre of local community life and the 2013 HangZhou UNESCO Declaration identified it as the pillar of economic, social and environmental sustainability. The study Cultural Heritage Counts for Europe, promoted by the European community and presented in Brussels in 2015, demonstrated how cultural heritage is also central to the processes of value production. Not only in terms of the revenues generated by the streams of public or cultural tourism, but also in terms of cultural heritage's contribution to continuous social innovation. The focus is not only on the tangible and physical assets, but also on the intangible ones. Richard Rogers affirmed: "culture gives meaning and pleasure to life. It encourages us to understand our place in history and helps us challenge established social convention. Urban regeneration, economic growth and cultural development are all inter-related" [1].

2018 was the European Year of Cultural Heritage (EYCH).

Thoughts and convictions stemming from very different historical and geographical contexts are confronting each other with increasing frequency, and therefore we asked ourselves whether the cultural values and ideals we relied on in the last century were also somehow changing. In the light of modernity and uncertainty, we probably have to redefine and reaffirm what we took for granted during the second half of the 20th century [2]. Let's take for example one of our Western cities - would we be able to truly and honestly say what we find ugly? Does the concept of beauty conform to a fashion or does it belong to something deeper? What is beauty? What remains of the beauty, then?

One of the aims of this research project is to investigate our current conditions through the concept of beauty, referring to what it means on an individual and global level. This investigation started in 2015 by questioning the rationale behind the habit of keeping rusty, ugly and inhospitable structures in place, instead of demolishing them. 
The concept of beauty is a long-standing philosophical question that does not have a definitive answer, but it can give incentives for personal and social improvement and reflection. This research's intention is to trigger discussions and queries rather than provide ultimate answers/solutions. The questions posed refer both to beauty and to the tactic of demolishing ugliness, and they refer in particular to the built space.

\section{EXPLORATIVE QUESTIONS}

The interviews (with experts, opinion leaders, citizens) open up a wide field of perception and concur in widening the definition of beauty and of an environment worth living. The narration of our perceptions, tastes and experiences of beauty creates awareness and knowledge, allowing for interactions among designers, architects and citizens.

The questions posed were always the same, i.e.: What is beauty for you? Where do you find beauty? Is beauty subjective or objective? What does the word demolition mean for you?

Beauty is in the eye of the beholder is a sentence that has existed for nearly 2300 years. To restate it in the words of those anonymous medieval scholars: de gustibus non disputandum est.

Is the concept of beauty really subjective then?

Recent works in the fields of neuroscience and behavioural psychology have begun to confirm that there are indeed means for measuring beauty by studying human responses and preferences. Not only do we make individual judgements about what we find beautiful, but we also hold within us predetermined criteria that lead us to make decisions that are not as personal as we might suppose [3]. To a large extent, researchers tell us, our judgements can be predicted. Preferences for certain shapes, colours, textures, materials and various other criteria can be tabulated and even ascribed to human qualities such as age, gender, cultural background and experience [4].

It is interesting to note how Matera, once considered shame of the world, was appointed European capital of Culture 2019. What was not demolished and cancelled out in the past, simply because it was too expensive, is now a place of precious beauty and tourism.

What is beauty then? Has heritage always to do with beauty?

"What is beauty and why do we need it? All thinking people recognise that this is a real question, and one of especial relevance in the disordered times in which we live. Indeed, in the case of the built environment, there is no question more urgent" wrote Sir Roger Scruton in 2019 [5].

\section{THE INTERVIEWS ON BEAUTY}

The interviews that compose this research are numerous, at the moment more than 60 people have given their views on the topic. Hereafter the answers of the experts who specifically deal with architecture and space, for their competencies and for the nature of their answers.

\subsection{Alfredo Brillembourg, architect, film maker, writer}

There is a nostalgic view of beauty based on proportions that comes from our western education. A lot of people do not like New York, Le Corbusier hated it, it is grey and messy. Others do not like Caracas, Lagos, Mumbai, but I love them. I would reflect on what Slavoj Zizek said. Human beings as an extension of nature should probably like what humans have produced the most, that is trash. So standing in front of a hill of trash we should reflect that this is what we have created in the name of progress. 
I believe that beauty somehow is an attitude. Beauty is the same with people and personality. I like imperfections, roughness, unfinished buildings. The early films of Wim Wenders give an idea of this concept of beauty in the built space. We should not emphasise on the nostalgic beauty, we should find it in all the leftovers spaces of the cities, the favelas, the slums, the villages. They have modularity.

Since Kant we have pushed an agenda of rationalization and science, thinking that this could bring order and harmony, we have lost our sense of understanding that science, poetry and art must be together. Architecture is one of the greatest arts as it encompasses everything and cities are the greatest examples of civilization. The beauty of cities is in the diversity. What makes a city interesting is the chiaroscuro. Without it we cannot manage cities.

In 1980s people were revaluating the classical language of architecture almost in nostalgic ways; in 1990s with globalization we were given a pattern of industrial architecture. After the twin towers tragedy, where the object of the attack was architecture, there is a break in societies. I find that the work of the architect should go more in the direction of roughness. Steel and concrete last and have character. We do not need decorations, we need what can withstand time.

I find beauty in Gaza where people have to share a very small space. Beauty is an expression of human endeavour and what it has produced. Beauty is something that impacts me, where human beings are taking over the space in a unique way, or are utilizing the space in an unusual way.

In the past beauty could be identified with form, today with process, with an expression of complexity.

\subsection{Mario Cucinella, architect}

Beauty is naturally associated to Italy, where it is very democratic: wherever you go there is beauty. Beauty is difficult to define because is intertwined with the codes of one's time. There is something that remains recognizable, however, over time, and is linked to the ability to also give profound contents beyond trends. I'm talking about solid content connected to the invisible, not just to the aesthetic aspects. But beauty is also something that is not seen, such as the care of space, or the secular Casentino beech-woods. There must be profound reasons for doing things in architecture that go beyond the form. As architects we must build with a vision of solidity, be aware of the responsibility we have in doing things and always consider their consequences. Aesthetics is not to be denied but has to embed the founding principles, beauty should be understood and realized, it should not be chased.

Demolishing is a beautiful word, I am for demolishing a lot. Too easy to criticize what has been done forty years ago. To build in excess for speculative reasons is useless, also, we don't need to reuse everything. Let's find the necessary courage to demolish and give value to the empty landscape.

\subsection{Dan Pitera, Dean of the School of Architecture, Detroit Mercy School}

For me beauty is how I feel, feeling joy and being passionate about what I do is beautiful, as well as it is beautiful being calm and at peace, relaxed. Beauty is all around me, external but also internal. It is not necessarily in what we see but in what we do. Working together is an example of beauty. It is not one thing or the other: it is the thing and the process, internal 
and external, something that brings a person joy, it is a noun and a verb, the system and the things, subjective and objective.

If an activity brings many people together and engages their passions, it is beautiful. To a child I would say that beauty is not fixed, it can change with knowledge, perspectives, complexity. Understanding the beauty of the complexity of life is the process of growing up. Beautiful things are complex, this is something that in architecture should be emphasised.

Demolition brings to mind a very strong attitude that people have in Detroit nowadays: they think that everything abandoned should be demolished or renovated to its original conditions. I think that there is a space in between. We could evaluate things differently: if there is something that is empty and abandoned and it is a symbol of negativity I can agree for its demolition. If a building brings great heritage we should keep it and renovate it to move forward.

As for myself, I do not demolish, I de-construct, i.e. I reuse fragments, I start off with something people think should be demolished and instead of demolishing I keep pieces and materials that can be reused and remove the rest. "Architectorial de-spoilure" is how we call this process. A building that should be demolished is basically blight in the landscape. But also an empty space after demolition can be blight in the space, because it can affect the citizens also on a psychological level. In thinking about demolition we should therefore think about all the consequences, not only physical ones, that's why we have to work in all the directions and in time.

\subsection{Jean Philip Vassal, architect}

Beauty is what we love. We start being interested in something, and by looking at it then beauty appears. To bring beauty in the world, you have to take care, to concentrate your attention and go beyond. You can see the most beautiful things in the worst situations. It is necessary to search for optimism, for closeness. When you feel with your body, with the sensibility to search and to generate the possibility to solve a problem.

I do not like the word Demolition. Poetry is a sort of demolition of words, it is a subtraction, a reduction, you keep only what is very important. It is a long poem that progressively is made essential. Many buildings are demolished because of their façade and not because of what they really are.

\subsection{Francesco Erspamer, Professor of Romance Languages and Literatures, Harvard}

The reason that truth and good are essential to a society is obvious. But for beauty it is not so obvious. Nevertheless has always been one of the three fundamental concepts for many civilizations. The fundamental question is not what beauty is, but why beauty. Kant, in the critique of judgment, introduces the idea of the universal subjective. Beauty is what allows you to have a subjective experience but having that experience entails that all others, as human beings like you, share, in the presence of this cathedral with this light at this moment, the same experience of beauty. Beauty is not something that you can look for, like an object, an experience, a truth, beauty is something that happens.

Recently I happened to discuss the beauty of some sporting gesture. The most beautiful things that I remember are those that have no purpose. A totally free gesture. There is a very significant episode of the Odyssey in which Ulysses tells of when he was about to leave for the war, with the fleet waiting to go to the Trojan war. But he stops because he sees a palm, he loses time in front of this palm. Observing this tree, meaningless in context, 
means that you are able to open up to other possibilities, not just those predictable. It is a metaphor for the fact that through beauty the perception of unpredictable, unusual solutions is exercised.

To Demolition I prefer the word change, evolution, but I don't think everything should be preserved. However, I don't like conceptually that replacing something with something new happens through a demolition process.

I mean, it's already so easy to demolish, time demolishes, everything breaks down. So I am against demolition, aware that anyway it happens.

\subsection{Pietro Guida, sculptor}

Beauty is the base element of life, it is a feeling that invades you completely. We are all able to notice beauty, it is an inner feeling; as for me, I feel it in my hands, I immediately want to reproduce it. Beauty is an absolute value, pleasure-ness instead is something that indulges in itself, shallow, and must be avoided. Demolishing is a reaction that cancels everything out, sometimes it is an exaggerated reaction, but it is useful to demolish oneself, one's ego.

\subsection{Michele Mari writer}

Beauty for me is the correspondence to one's own mental scheme, and it brings to me emotions like the desire for possession, I find beauty in the trees, in the music and if I have to think of an urban environment, of the city, I find beautiful everything that is not sparkling, dynamic, contaminated by advertising and specifically I find beauty in old houses. In fact, I don't recognize my city, Milan, as beautiful. Beauty is objective, it is in the canons that we have within us even though we have not created them. The canons evolve slowly and collectively, but we have them inside. I would demolish everything that is abusive and everything that rapes the landscape.

\subsection{Moni Ovadia, actor, singer, artist}

Beauty is the attention to the fragility of others, of life itself. Beauty in a word is interiority and is always amazing, it is care. Beautiful is a look, a glimpse of nature, in my daily life I find it in the mutual respect. All the places of justice are beautiful, beauty is both subjective and objective.

\subsection{Andrea Semplici, photographer}

Beauty for me is a deep emotion, adrenaline, heart beating, butterflies in the stomach. Beautiful is also a moment of silence, it is meeting people who surprise me, people who bring their own light. The adventure of travelling for me is beauty, a kinetic balance that I compare to running on the rocks, the balance is given by speed, if you stop you fall down. For me, beauty is also this continuous movement and is both objective and subjective. A child who touches an old tree could appreciate the beauty, understand it by touch. I once saw a poet who recited poetry aloud on his own, believing he was not seen, I find this a beautiful thing.

I like the idea of demolishing walls, houses, and getting rid of ourselves, our smallness, so we have something to demolish every night. 


\section{CONSIDERATIONS}

After analyzing the answers there are perhaps two important aspects we found out: there is taste, which is personal, subjective, and which concerns the strictly aesthetic aspect of something, its pleasantness, and then there is beauty, which functions as the trigger of an emotion shared, in a certain sense, by everyone. So, we can say that it is the experience of what we like, the sentiment of beauty, that unites us all (as the research of Zeki et al. [6] confirms) and is triggered by what we like. This sentiment is common to us all. I may like flowers and a sunset, you may like mountains, heavy metal music and a dinosaur, but we feel the same thing. On the other hand, our interviews underline how the word Demolition of ugliness is at times associated with negative thoughts but also with the idea of making space for something else, new and refreshing.

Why the concept of beauty is important in the city? Beauty in architecture brings us joy and happiness. Merriam-Webster defines beauty as "qualities in a person or thing that gives pleasure to the senses or pleasurably exalts the mind or spirit." Or more to the point, Stendhal, the 19th century French writer, wrote, "Beauty is the promise of happiness." And happiness is one of our fundamental human needs. Beauty is then more robust than it seems.

Padelford in [7], "I think that we are not at all aware of the immense social asset that uniformly good architecture would be. Fancy a city in which all of the buildings are beautiful, and trace the influence on the lives of the inhabitants. In the first place, it would add greatly to the happiness of people, for, as has been observed, it is the normal function of beauty to make us happy. Unless we have allowed ourselves to become diseased, happiness will attend beauty as naturally as flowers turn to the sun."

De Botton in The architecture of Happiness [8] writes: "The buildings we admire are ultimately those which, in a variety of ways, extol the values we think worthwhile - which refer, that is, whether through materials, shapes or colours, to such legendary positive qualities as friendliness, kindness, subtlety, strength and intelligence. Our sense of beauty and our understanding of the nature of a good life are intertwined."

Beauty is not the exclusive property of the landed and wealthy. It belongs to us all or it should do. We should strive to ensure that every citizen, however deprived or disadvantaged, has a proper share of it. At present this is not happening. Beauty is unequally distributed. "Beauty comprehends all that feeds into the sense of being at home in a shared world. People make sacrifices for beauty as they do for love. (...) Beauty includes everything that promotes a healthy and happy life, everything that makes a collection of buildings into a place, everything that turns anywhere into somewhere, and nowhere into home. (...) Whereas ugliness means buildings that are unadaptable, unhealthy and unsightly, and which violate the context in which they are placed" [9].

Stemming from what written so far, this is a tentative definition of beauty in the built space. The beauty of cities, in cities, is in their diversity, it's a process that explores complexity, that needs the responsibility of the architect, the builder, the citizen. It is in the ability to give content beyond any trend, it is in the invisible, in the care and attention devoted to the space, the community, mankind. It is in the joy of realizing one's desires, it is in the passion for knowledge and sharing space and life. Beauty is what we love, what we end up loving after close search, with generosity and attention. Beauty happens, but we have to be prepared to experience it, to feel it. It is in a space of justice and joy. Beauty is, despite everything else, even when not seen. In the built space it is the ability to build for the community, with the best available materials, as an inviolable refuse of ugliness. 


\section{REFERENCES}

[1] Bianchini, F. \& Parkinson, M. (eds), Cultural Policy and Urban Regeneration: The West European Experience, Manchester University Press, 1994.

[2] Kühtz, S. \& Rizzi, C., The Demolishers Manifesto - What Remains of the Beauty the Choice of the Architect, ed. Spagine, Lecce, 2019.

[3] Ishizu, T. \& Zeki, S., Toward a brain-based theory of beauty. PLoS ONE, 6(7), p. e21852, 2011.

[4] Grice, G.S., Why are some buildings so ugly? OAA Perspectives, p. 8, Oct. 2012.

[5] Scruton, R., The need for beauty. Building Beautiful - A Collection of Essays on the Design, Style and Economics of the Built Environment, ed. J. Airey, Policy Exchange, 2019.

[6] Zeki, S., Romaya, J.P., Benincasa, D.M.T. \& Atiyah, M.F., The experience of mathematical beauty and its neural correlates. Frontiers of Human Neuroscience, $\mathbf{8}$, p. 68, 2014.

[7] Padelford, F.M., The civic control of architecture. American Journal of Sociology, pp. 45-46, Jul. 1908.

[8] De Botton, A., The Architecture of Happiness, Knopf Doubleday Pub, 2008.

[9] Living with beauty: Report of the Building Better, Building Beautiful Commission, Jan. 2020. 